\title{
Diet cost and quality using the Healthy Eating Index-2015 in adults from urban and rural areas of Mexico
}

\author{
Katherine Curi-Quinto ${ }^{1}$ (D), Mishel Unar-Munguía ${ }^{1, *}$ (), Sonia Rodríguez-Ramírez ${ }^{1}$ (1), \\ Elin Röös ${ }^{2}$ (10, Walter C Willett ${ }^{3}$ and Juan A Rivera ${ }^{4}$ (1) \\ ${ }^{1}$ Center for Research on Nutrition and Health, National Institute of Public Health, Cuernavaca, Morelos, Mexico: \\ ${ }^{2}$ Department of Energy and Technology, Swedish University of Agricultural Sciences, Uppsala, Sweden: ${ }^{3}$ Department \\ of Nutrition, Harvard School of Public Health, Boston, MA, USA: ${ }^{4}$ National Institute of Public Health, Cuernavaca, \\ Morelos, Mexico
}

Submitted 23 January 2021: Final revision received 15 August 2021: Accepted 28 October 2021: First published online 24 November 2021

\begin{abstract}
Objective: To assess the association between diet cost and quality by place of residence.

Design: We analysed cross-sectional data of the National Health and Nutrition Survey-2012. Diet cost was estimated by linking dietary data, obtained from a 7-d SFFQ, with municipality food prices, which were derived from a national expenditure survey. Diet quality was assessed using the Healthy Eating Index2015 (HEI-2015). Association between quintiles of diet cost and HEI-2015 was assessed using linear regression analysis.

Settings: Mexico.

Participants: 2438 adults (18-59 years).

Results: Diet cost was positively associated with diet quality (HEI-2015) in urban but not in rural areas. Compared with quintile (Q1) of cost, the increment in diet quality score was $1 \cdot 17(95 \% \mathrm{CI}-0 \cdot 06,4 \cdot 33)$ for Q2, $2 \cdot 14(95 \% \mathrm{CI}-0 \cdot 06,4 \cdot 33)$ for Q3, 4.70 (95\% CI 2.62, 6.79) for Q4 and 6.34 (95\% CI 4.20, 8.49) for Q5 ( $P$-trend < $0 \cdot 001)$. Individuals in rural $v$. urban areas on average have higher quality diets at lower cost with higher intakes of whole grains and beans and lower intakes of $\mathrm{Na}$, added sugars and saturated fats. Living in the South, being indigenous and having low socio-economic status were also associated with higher quality diets.

Conclusions: Diet cost was positively associated with diet quality, but only in urban areas. Further studies are needed to understand the relation between diet cost and quality in rural areas. To improve overall diet quality in Mexico, strategies that aim to reduce the cost of high-quality diets should consider the heterogeneity by place of residence.
\end{abstract}

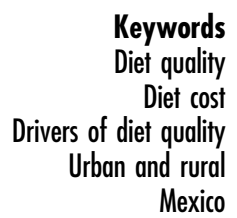

Higher prices for healthy food could become a barrier to adopting high-quality diets. This is because food prices are a major driver of food choices that affects food affordability and imposes budgetary restrictions on household purchases ${ }^{(4)}$. This could partly explain the dietary and health disparities observed among vulnerable populations ${ }^{(5)}$. Most of the evidence about the relationship between diet cost and quality comes from highincome countries, showing that high-quality diets are more expensive than low-quality diets ${ }^{(6)}$. However, little is known about this relationship in low- and middleincome countries and vulnerable populations. There is 
evidence that for rural and indigenous people, highquality diets can be more affordable than those of low quality $^{(7-9)}$. Also, in some ethnic populations, higher quality diets could be achieved at a lower cost compared with diets followed by the average population ${ }^{(10,11)}$. This variability confirmed the need to better understand the association between the cost and quality of diets in different contexts, which is particularly important in low- and middle-income countries that are more affected by changes in income and food prices than high-income countries $^{(12)}$. Also, low- and middle-income countries are in a rapid but not homogenous process of nutrition transition, associated with socio-economic and cultural characteristics within the country that could hinder the effectiveness of policies intended to improve diet quality in those contexts.

In Mexico - a middle-income country - there is a high prevalence of non-communicable diseases, particularly in the adult population $(75.2 \%$ had excess weight, $18.4 \%$ had hypertension and $10.3 \%$ had diabetes in 2018) ${ }^{(13)}$. Most of the evidence about diet quality has been evaluated using a posteriori characterisation of food patterns and by assessing adherence to recommendations for nutrients or food groups ${ }^{(14,15)}$. However, few studies have evaluated the overall quality of diet using a priori dietary indices, and there is no validated method to measure diet quality such as the Healthy Eating Index-2015 (HEI$2015)^{(16)}$. This index considers the potential interaction of diet components and assesses diet quality using predefined criteria based on dietary recommendations for disease prevention. This allows diet quality to be compared among groups and identify their associated factors $^{(17,18)}$. Also, in a multiethnic cohort from the USA, higher values of the HEI-2015 were associated with a lower risk of all-cause mortality, CVD and cancer in adults $^{(19)}$.

Furthermore, a few studies suggested that less healthier foods are less costly and more affordable than healthier options in Mexico ${ }^{(20,21)}$. Despite this evidence, higher prices on individual healthy food products do not imply that the overall cost of a high-quality diet will be higher because people choose and combine food and beverages of different qualities and prices. Moreover, knowledge is still limited regarding a more comprehensive assessment of the overall quality of the Mexican diet and its relation with diet cost, especially considering differences by place of residence. This is important since differences in food intake and prices have been observed by place of residence; traditional food is more common in rural areas while a 'western style diet' is more frequent in urbanised $\operatorname{areas}^{(21)}$, and the cost of a basic food basket is higher in urban than in rural areas ${ }^{(22)}$. Therefore, the aim of this study was to assess the association between diet cost and quality among the Mexican adult population (18-59 years) and to examine whether the association varies by place of residence.

\section{Methods}

\section{Study population and dietary information}

This was a cross-sectional study based on the analysis of dietary and socio-demographic data from adult (18-59year-old) participants of the National Health and Nutrition Survey 2012 (Encuesta Nacional de Salud y Nutrition or ENSANUT-2012 by its Spanish acronym) that was conducted between October 2011 and May 2012. This is a stratified and multi-stage random survey with representativeness at national, state and rural/urban levels ${ }^{(23)}$. The dietary data were obtained from a 7-d semi-quantitative FFQ (SFFQ) collected by trained interviewers using a standardised methodology ${ }^{(24)}$. The SFFQ was validated with a 24-h recall and included 140 food items classified into fourteen groups that contributed to more than $90 \%$ of total energy and nutrient intake ${ }^{(24)}$. The study protocol of ENSANUT was approved by the Ethics Committee of the National Institute of Public Health in Mexico (INSP by its Spanish acronym), and only participants who agreed and signed an informed consent were included in the survey.

\section{Selection of the analytical sample}

Our analytical sample consisted of all adults with complete dietary and socio-demographic data. From an initial sample of 2792 adults (18-59-year-olds) with SFFQ data, we excluded 147 pregnant or lactating women and 207 adults with implausible nutrient intakes (see online supplementary material, Supplemental Fig. 1). We did not consider older adults in the analytical sample (526 individuals $>60$ years old) because their dietary intake could be more affected by their physiological condition and potential health problems compared with younger adults ${ }^{(25,26)}$.

The identification of implausible data is fully described elsewhere ${ }^{(24)}$. Briefly, we excluded adults that either reported: (1) intakes in grams of one or more foods above $3 \mathrm{SD}$, (2) ratios between the intake of energy, macro and micronutrients and their respective required intake above $3 \mathrm{SD}$ and (3) ratios of energy intake to BMR below 0.5.

\section{Assessment of diet quality}

We used the HEI-2015 ${ }^{(27)}$, which is a validated method to assess overall diet quality and its individual dietary components by assigning a score according to adherence to the latest Dietary Guidelines for Americans, which reflects international scientific recommendations to promote better food patterns and reduce the risk of non-communicable diseases ${ }^{(28)}$. The HEI-2015 includes thirteen dietary components divided into nine adequacy components: total fruits, whole fruits, total vegetables, greens and beans, whole grains, dairy products, total protein foods, seafood and plant proteins and fatty acids (a ratio of PUFA and MUFA to SFA), for which higher scores represent higher intakes, and four moderation components (refined grains, Na, 
added sugars and saturated fats), for which higher scores represent lower consumption ${ }^{(29)}$. Each component contributes $0-5$ or $0-10$ points to the total HEI-2015 score which ranges from 0 to 100 points. In the food grouping, we did not double count the group of greens and beans in the group of total protein and in the group of seafood and plant proteins. Therefore, the first group only included animal food protein and the second group included seafood, seeds and nuts. Details of the food groups and the scoring method are shown in online supplementary material, supplemental Table 1.

To calculate the HEI-2015 for each individual, we followed the procedures described in the National Cancer Institute website ${ }^{(29)}$. Briefly, we calculated the amount of each HEI-2015 dietary component expressed by its equivalent unit, which assesses adherence to dietary recommendations (see online supplementary material, Supplemental Table 1). The equivalent units for food groups were obtained from the 'Food Patterns Equivalents Database 2013-14 ${ }^{(30)}$. In the case of dishes, we first disaggregated them into ingredients using standardised recipes developed by the INSP. For nutrients (fatty acids, Na, saturated fats), we calculated their total intake based on the INSP's food composition table. For added sugar, we used the method proposed by Louie et al. ${ }^{(31)}$. In brief, the content of added sugar was zero for foods without sugar or whose sugar is only intrinsic (i.e. fruits); in foods where the main component was added sugar like sweets, the added sugar was equal to the total sugar content. For foods with a mixed content of sugar (intrinsic and added), such as natural juices with sugar, the added sugar was estimated based on standardised recipes developed by the INSP. For processed foods such as yogurt, the content of added sugar was based on the Nutrient Profile Model of the Pan American Health Organization $^{(32)}$.

\section{Assessment of food prices and diet cost}

Our estimation of food prices considered differences between rural and urban areas and was made at the municipal level using data from the National Survey of Household Income and Expenditure 2012 (Encuesta Nacional de Ingresos y Gastos de los Hogares or ENIGH 2012 by its Spanish acronym). This survey has a stratified probabilistic design with national representativeness for urban and rural areas and provides information on the quantity of food and beverages purchased and expenditures per household during the last week. This information is self-reported by the head of the household and includes a list of 220 most consumed food and non-alcoholic beverage items which are considered in the Mexican basic food basket to assess the Consumer Price Index and food poverty lines ${ }^{(33)}$.

We estimated the price per $100 \mathrm{~g}$ of each food and beverage by dividing the total monetary expenses for each item by the quantity in grams purchased by household. For milk provided by the national program 'Liconsa', we used its subsidised price for $2012^{(34)}$. Then we estimated the median price of each food and beverage at the municipality level. For the sixty-three foods and beverages (28.6\% of items) whose prices at municipality level were missing since no purchases were reported, we assigned the median of food prices at the state level (fifty-eight items) or urban/ rural area (six items) when food prices were also missing at the state level. To reduce the potential error in the estimation of prices, we excluded food and beverage items whose quantities and prices were in the first or the ninety-ninth percentile of the distribution. Prices above 2 SD were replaced by the average price for each food item plus $2 \mathrm{SD}^{(35)}$. All prices were deflated to 2018 using the National Consumer Price Index ${ }^{(35)}$. All of the 161 SFFQ food and beverage items reported in ENSANUT-2012 were matched manually with the most closely related food and beverage item reported in ENIGH, considering their ingredients and nutritional composition. Most of the SFFQ food items were matched with one specific ENIGH item, although some foods such as beef, pork, chicken offal, cheese and mixed sausage were paired with the average of the different cuts or subtypes of meat reported in the ENIGH. Additionally, we converted the quantity of the SFFQ from as-eaten to raw weight using conversion factors from the National Institute of Public Health, since purchased food and beverages are expressed in raw weight in the ENIGH. Food and beverage prices at the municipality level were linked to each individual in ENSANUT-2012 considering their geographical residence. For municipalities in ENSANUT-2012 for which prices were lacking in ENIGH, we assigned the prices of the nearest municipality based on the geographical coordinates for each municipality provided by INEGI-2010, using the Stata module 'Geonear' to calculate the geodetic distances between municipalities ${ }^{(36)}$. Finally, the daily diet cost per person was estimated by adding the multiplication of the price by the quantity consumed of each food item and adjusting to $8368 \mathrm{~kJ}$ (2000 kcal). For the sensitivity analysis, we used the food prices of INEGI 2012 (National Institute of Statistics and Geography), collected in forty-six urban cities (population above 20000 habitants), which are used to calculate the Consumer Price Index in Mexico ${ }^{(35)}$.

\section{Socio-demographic variables}

We included sex (male/female), age in tertiles, socioeconomic status (SES) in tertiles; education level categorised as low (elementary school or no education), medium (high school) and high (university); ethnicity (indigenous and non-indigenous) and place of residence (urban/rural area and region). The SES was based on an index of household well-being constructed by ENSANUT using principal component analysis of household characteristics, goods and services ${ }^{(37)}$. Ethnicity was categorised as indigenous (when the adult speaks any indigenous language) or nonindigenous $^{(38)}$. Residence area was defined as rural 
(locations with $<2500$ inhabitants) or urban (locations with $\geq 2500$ inhabitants) ${ }^{(39)}$, and region of residence was divided into the North, Centre, Mexico City and South.

\section{Statistical analysis}

Descriptive analysis was presented using proportions and means with $95 \%$ CI. We compared the mean of dietary components by the lowest (Q1), middle (Q3) and highest (Q5) quintiles of diet cost using the ANOVA and the Bonferroni post hoc analysis for multiple comparison. We stratified the analysis by urban and rural areas if the interaction between area of residence and diet cost was statistically significant $(P$-value $<0.05)$. To assess the association between quintiles of diet cost and diet quality, we estimated three regression models: (1) crude, (2) adjusted by socio-demographic variables and (3) including the region and the interaction term between cost and area to examine whether the association varied by area of residence.

Sensitivity analysis examined whether the association between diet cost and diet quality could be affected by the source of prices (ENIGH $v$. INEGI prices) as well as the inclusion of the total energy intake as a covariate in the analyses. A $P$-value $<0.05$ was considered as statistically significant, and all analyses were conducted in Stata software v.14 using the 'svy' prefix for complex surveys. We calculated the adjusted diet quality means using the margin command in Stata.

\section{Results}

The means of HEI-2015 and diet cost by socio-demographic characteristics are shown in Table 1 . The mean HEI-2015 score of the overall sample was 54.1 (95\% CI $53.5,54.7)$, and the mean of diet cost was 52.1 Mexican pesos $(\$ M X N)$ per $8368 \mathrm{~kJ}(2000 \mathrm{kcal})(95 \%$ CI 51.1, 53.0). Significant differences in mean quality and cost of diet by SES, education, area, region and ethnicity were observed. When we examined the HEI-2015 of the lowest, middle and highest quintiles of diet cost, adults from rural areas had higher HEI-2015 scores than those in urban ones (Table 2). Furthermore, the mean HEI-2015 scores for fruits, vegetables, dairy products, total protein food, seafood and plant protein, and refined grains were higher among higher quintiles of diet cost in both rural and urban areas $(P<0.05)$. By contrast, the HEI-2015 scores for greens and beans, whole grains, fatty acids (a ratio of PUFA and MUFA to SFA), Na, added sugars and saturated fats were lower among higher quintiles of diet cost $(P<0.05)$ (Table 2).

In the analysis of associations between diet cost and the HEI-2015, we identified a significant interaction between area of residence and diet cost (see online supplementary material, Supplemental Table 2), so we presented the results stratified by area of residence in Table 3. In urban areas, a higher diet cost was associated with a higher HEI-2015 score in quintiles of cost Q3, Q4 and Q5 v. Q1, but in rural areas, the association between diet cost and diet quality was not statistically significant for any cost quintile (Table 3). Despite these results, we observed a large area of overlap between the distribution of the HEI-2015 by low, middle and high quintiles of diet cost in both urban and rural areas (Fig. 1).

As can be seen in Fig. 2, when stratifying the analysis by region and area of residence, we found that the positive association between diet cost and quality was stronger in urban areas of the North, Mexico City and the Centre region, as shown by the large difference in the values between quintiles of diet cost. Differences in the score of diet quality between the highest $v$. the lowest cost quintiles were 11.06 (95\% CI 6.78, 15.35), 7.91 (95\% CI 2.97, 12.84) and 5.20 (95\% CI 1.94, 8.45) points, respectively, while in the Southern region, the difference was 2.56 (95\% CI 1.54, 6.66) (see online supplementary material, Supplemental Table 3). No statistically significant associations were seen in rural areas of any region.

Having a medium $v$. low SES was associated with a lower diet quality in urban areas, while in rural areas having a high $v$. low SES was associated with lower diet quality, maintaining the constant average cost of diet (Table 3). The highest quintiles of cost had on average a higher HEI-2015 score in all levels of SES in urban but not in the rural areas (see online supplementary material, Supplemental Fig. 2).

Additionally, both in urban and rural areas, being indigenous compared with non-indigenous was associated with a higher diet quality. No associations were found between sex and education with diet quality (Table 3).

The sensitivity analysis using prices from INEGI-2012 showed a similar trend in the relation between diet quality and diet cost in urban and rural areas; however, the coefficients in urban areas were attenuated (see online supplementary material, Supplemental Table 4). When adjusting by energy intake, we found similar results in rural areas (see online supplementary material, Supplemental Tables 6 and 8 ), but in urban areas, we found larger association coefficients (see online supplementary material, Supplemental Tables 5 and $\mathrm{S}$ ).

\section{Discussion}

We found that the association between diet cost and diet quality differed by urban/rural area and region in Mexico. No association between diet cost and quality was observed in rural areas, while in urban areas, there was a positive association with stronger magnitude in the North, Centre and Mexico City compared with the Southern region. Our results highlight the existence of a broad overlap in the distribution of diet quality across 
Table $1 \mathrm{HEl}-2015$ and diet cost among adults (18-59 years) by socio-demographic characteristics, ENSANUT-2012

\begin{tabular}{|c|c|c|c|c|c|c|}
\hline & \multirow[b]{2}{*}{$n$} & \multirow[b]{2}{*}{$\% \ddagger$} & \multicolumn{2}{|c|}{ HEI-2015§ score } & \multicolumn{2}{|c|}{$\begin{array}{l}\text { Daily diet cost } \\
\text { (\$MXN/8368 kJ) }\end{array}$} \\
\hline & & & Mean & $95 \% \mathrm{Cl}$ & Mean & $95 \% \mathrm{Cl}$ \\
\hline \multicolumn{7}{|l|}{ Population } \\
\hline Total sample & 2438 & 100 & $54 \cdot 1$ & $53 \cdot 5,54 \cdot 7$ & $52 \cdot 1$ & $51 \cdot 1,53 \cdot 0$ \\
\hline \multicolumn{7}{|l|}{$\operatorname{Sex}(\%)$} \\
\hline Male & 1029 & 47 & 53.6 & $52 \cdot 7,54 \cdot 6$ & $51 \cdot 1$ & $49 \cdot 8,52 \cdot 4$ \\
\hline Female & 1409 & 53 & 54.5 & $53 \cdot 7,55 \cdot 3$ & 53.0 & $51 \cdot 7,54 \cdot 2^{*}$ \\
\hline \multicolumn{7}{|l|}{ Age group (years) } \\
\hline $18.0-<29.6$ & 869 & 33 & $53 \cdot 0$ & $51 \cdot 9,54 \cdot 1$ & $52 \cdot 1$ & $50 \cdot 8,53 \cdot 3$ \\
\hline $29.6-<43.5$ & 818 & 33 & 54.9 & $53 \cdot 9,55 \cdot 9^{*}$ & $52 \cdot 8$ & $51 \cdot 2,54.5$ \\
\hline $43 \cdot 5-59 \cdot 0$ & 751 & 33 & $54 \cdot 3$ & $53 \cdot 2,55 \cdot 4$ & $51 \cdot 3$ & $49 \cdot 6,52 \cdot 9$ \\
\hline \multicolumn{7}{|l|}{ Education level (\%) } \\
\hline Low & 112 & 4 & $57 \cdot 6$ & $54 \cdot 7,60.5$ & 47.5 & $43 \cdot 2,51 \cdot 7$ \\
\hline Medium & 1561 & 63 & $54 \cdot 2$ & $53 \cdot 4,54.9^{\star}$ & $49 \cdot 0$ & $47 \cdot 9,50 \cdot 0$ \\
\hline High & 765 & 33 & 53.5 & $52 \cdot 3,54 \cdot 6^{*}$ & 58.6 & $57 \cdot 0,60 \cdot 2^{*}, \dagger$ \\
\hline \multicolumn{7}{|c|}{ Socio-economic level (\%) } \\
\hline Low & 818 & 25 & $57 \cdot 8$ & $56 \cdot 7,58 \cdot 9$ & $45 \cdot 3$ & $44 \cdot 0,46 \cdot 7$ \\
\hline Medium & 820 & 33 & 52.9 & $51 \cdot 9,54 \cdot 0^{*}$ & $51 \cdot 3$ & $49 \cdot 9,52 \cdot 7^{\star}$ \\
\hline \multicolumn{7}{|l|}{ region (\%) } \\
\hline North & 612 & 21 & $49 \cdot 7$ & $48 \cdot 6,50 \cdot 9$ & $55 \cdot 3$ & $53 \cdot 3,57 \cdot 4$ \\
\hline Centre & 871 & 32 & $55 \cdot 1$ & $56 \cdot 6,58 \cdot 6^{*}$ & $52 \cdot 6$ & $50 \cdot 9,54 \cdot 3^{*}$ \\
\hline Mexico City & 124 & 17 & 51.0 & $51 \cdot 2,55 \cdot 1 \dagger$ & 53.3 & $50 \cdot 2,56 \cdot 5$ \\
\hline South & 831 & 31 & $57 \cdot 7$ & $59 \cdot 3,61 \cdot 5^{\star}, \dagger, \|$ & $48 \cdot 7$ & $47 \cdot 3,50 \cdot 0^{*}, \dagger$, \\
\hline \multicolumn{7}{|c|}{ Residence area (\%) } \\
\hline Urban & 1636 & 77 & $52 \cdot 4$ & $51 \cdot 7,53 \cdot 1$ & $54 \cdot 0$ & $52 \cdot 8,55 \cdot 2$ \\
\hline Rural & 802 & 23 & 59.7 & $58 \cdot 6,60 \cdot 8^{*}$ & $45 \cdot 8$ & $44.3,47 \cdot 3^{\star}$ \\
\hline \multicolumn{7}{|l|}{ Ethnicity (\%) } \\
\hline Indigenous & 216 & 7 & $62 \cdot 2$ & $60 \cdot 0,64.5$ & $46 \cdot 2$ & $43 \cdot 1,49 \cdot 4$ \\
\hline Non-indigenous & 2222 & 93 & 53.5 & $52 \cdot 8,54 \cdot 1^{\text {* }}$ & 52.5 & $51.5,53.5^{\star}$ \\
\hline
\end{tabular}

HEI-2015, Healthy Eating Index-2015.

*Indicates significant difference with the first category.

†Indicates significant difference with the second category.

$\neq$ Percentage of the expanded population size ( $n 51807582$ ).

$\S$ Healthy Eating Index-2015. This indicator was used to assess the overall diet quality that ranges from 0 to 100.

IIIndicates significant difference with the third category. The significance was assessed at $P<0.05$ using a $t$ test for mean comparison.

levels of diet cost, indicating that it is possible to have a high-quality diet without increasing its cost. Also, adults living in rural $v$. urban areas, in the South $v$. Northern region, those with low $v$. high SES and indigenous $v$. nonindigenous had a higher quality diet.

To our knowledge, this is the first study that analysed the association between diet cost and overall diet quality in Mexico using a HEI. A previous national study from Mendoza et al. analysed this association using energy density as an indicator of diet quality and found that diets with lower energy density were associated with a higher diet cost with no differences by place of residence ${ }^{(21)}$. We also found that higher quality diets cost more than lower quality ones, but only in urban areas. One difference with our study is that, in contrast to the HEI-2015, energy density is not a measure of overall diet quality, since it measures only one characteristic of the diet without considering recommendations regarding other dietary components ${ }^{(40)}$. In comparison with international data, studies that come mainly from high-income countries reported the same association we observed in urban areas, regardless of the metric used to assess diet quality ${ }^{(6)}$. Also, populationbased studies using a method similar to the HEI-2015 reported that higher diet cost was associated with higher quality diets ${ }^{(10,11,41,42)}$. However, as we reported here, a study conducted in adult females from the USA highlighted that diet quality could be improved without increasing the diet $\operatorname{cost}^{(11)}$. We also found that the association between diet cost and diet quality in urban areas varies by region, showing a stronger association in the most urbanised and wealthier regions (North and Mexico City), compared with the South, which is the poorest region of the country. In contrast, the studies from the USA that mostly analysed urbanised context did not report any differences by states, instead it reported a strongest positive relation of diet quality and diet cost by $\operatorname{sex}^{(10,11,41,42)}$.

Our findings also showed no significant association between diet cost and diet quality in rural areas, which could be due to less variability in food prices in comparison to urban areas or due to a greater measurement error in prices in rural areas using the ENIGH. However, in a sensitivity analysis using INEGI's prices from the country's major cities, the same source of prices as Mendoza et $a l^{(21)}$, our results did not change. At the international level, few studies have analysed the relationship between diet cost and diet quality in rural areas. One study from the 


\section{Public Health Nutrition}

Table 2 Mean score of HEI-2015 and dietary components by diet cost tertiles and area of residence, ENSANUT-2012

\begin{tabular}{|c|c|c|c|c|c|c|c|c|c|c|c|c|c|}
\hline \multirow[b]{4}{*}{ Daily diet cost (\$MXN/2000 kcal) } & \multicolumn{13}{|c|}{ Quintiles of diet cost (\$MXN/2000 kcal) } \\
\hline & \multicolumn{7}{|c|}{ Urban $(\text { mean } \pm S D)^{*}$} & \multicolumn{6}{|c|}{ Rural (mean $\pm \mathrm{SD})^{*}$} \\
\hline & \multirow[t]{2}{*}{ Maximum HEI-2015 } & \multicolumn{2}{|c|}{$\begin{array}{l}\text { Lowest (Q1) } \\
\quad(n \text { 407) }\end{array}$} & \multicolumn{2}{|c|}{$\begin{array}{l}\text { Middle (Q3) } \\
\quad(n \text { 574) }\end{array}$} & \multicolumn{2}{|c|}{$\begin{array}{c}\text { Highest (Q5) ( } n \\
655)\end{array}$} & \multicolumn{2}{|c|}{$\begin{array}{c}\text { Low (Q1) }(n \\
404)\end{array}$} & \multicolumn{2}{|c|}{$\begin{array}{l}\text { Middle (Q3) } \\
\quad(n \text { 236) }\end{array}$} & \multicolumn{2}{|c|}{$\begin{array}{c}\text { High (Q5) ( } n \\
162)\end{array}$} \\
\hline & & $35 \cdot 0$ & 4.5 & $51 \cdot 2$ & $2 \cdot 1^{*}$ & 73.7 & $12 \cdot 1^{*}, \dagger$ & 33.2 & $5 \cdot 1$ & $50 \cdot 6$ & $2 \cdot 0^{*}$ & $70 \cdot 2$ & $8 \cdot 8^{\star}, \dagger$ \\
\hline HEl-2015 mean score & 100 & $50 \cdot 2$ & $10 \cdot 3$ & $51 \cdot 2$ & $10 \cdot 3^{*}$ & $55 \cdot 6$ & $9 \cdot 5^{\star}, \dagger$ & $61 \cdot 3$ & $12 \cdot 2$ & $59 \cdot 1$ & $10 \cdot 9^{*}$ & $57 \cdot 8$ & $9 \cdot 7^{*}, \dagger$ \\
\hline Daily energy intake (kcal) & & 1820 & 581 & 1991 & 692 & 1707 & $664 t$ & 1797 & 582 & 1744 & $663^{*}$ & 1650 & $571 \dagger$ \\
\hline \multicolumn{14}{|l|}{ Score for adequacy components } \\
\hline Total fruits $\ddagger$ & 5 & $2 \cdot 16$ & 1.71 & 3.00 & $1.85^{\star}$ & 3.94 & $1.58^{\star}, \dagger$ & $2 \cdot 23$ & 1.73 & 3.65 & $1.44^{*}$ & 3.67 & $1.80^{*}, \dagger$ \\
\hline Whole fruits§ & 5 & 3.04 & 2.04 & 3.65 & $1.78^{\star}$ & 4.30 & $1.49^{*}, \dagger$ & $3 \cdot 15$ & 1.88 & 4.42 & $1 \cdot 25^{\star}$ & 4.13 & $1.48^{*}, \dagger$ \\
\hline Total vegetables\|l & 5 & 1.82 & 1.07 & $2 \cdot 69$ & $1 \cdot 37^{\star}$ & 3.68 & $1 \cdot 34^{*}, \dagger$ & 1.98 & 1.25 & 2.95 & $1 \cdot 38^{*}$ & 3.45 & $1.55^{\star}, \dagger$ \\
\hline Greens and beans & 5 & 2.94 & 1.76 & 2.48 & $1.68^{\star}$ & $2 \cdot 27$ & $1.68^{*}$ & 3.56 & 1.77 & 2.96 & $1.87^{\star}$ & 3.52 & $1.73^{*}, \dagger$ \\
\hline Whole grains & 10 & $4 \cdot 19$ & 3.92 & 3.48 & 3.66 & 3.10 & $3 \cdot 19^{*}$ & $7 \cdot 40$ & 4.04 & 4.47 & $4 \cdot 20^{*}$ & 5.02 & $4 \cdot 15^{\star}, \dagger$ \\
\hline Dairy products** & 10 & $2 \cdot 63$ & 2.50 & 4.01 & $2 \cdot 91^{*}$ & 5.48 & $3 \cdot 22^{*}, \dagger$ & $2 \cdot 24$ & $2 \cdot 63$ & 4.29 & $2 \cdot 91^{\star}$ & 4.89 & $3 \cdot 38^{*}, \dagger$ \\
\hline Total protein food $\dagger \dagger$ & 5 & 2.00 & 1.13 & 3.24 & $1 \cdot 31^{*}$ & 3.63 & $1.38^{*}, \dagger$ & 1.74 & $1 \cdot 16$ & 3.01 & $1.46^{\star}$ & 3.41 & $1.35^{\star}, \dagger$ \\
\hline Seafood and plant protein $\ddagger \ddagger$ & 5 & 0.45 & 1.08 & 0.89 & $1 \cdot 41^{*}$ & 1.47 & $1.76^{*}, \dagger$ & 0.64 & $1 \cdot 21$ & 0.96 & 1.68 & $1 \cdot 16$ & $1.61^{*}, \dagger$ \\
\hline Fatty acids§§ & 10 & $4 \cdot 20$ & $3 \cdot 26$ & $3 \cdot 13$ & $3.07^{\star}$ & $2 \cdot 38$ & $2 \cdot 55^{\star}, \dagger$ & $5 \cdot 67$ & $3 \cdot 76$ & 3.72 & $3.00^{*}$ & $2 \cdot 37$ & $2 \cdot 54^{*}, \dagger$ \\
\hline \multicolumn{14}{|l|}{ Score for moderation components|III } \\
\hline Refined grains & 10 & $2 \cdot 18$ & $3 \cdot 72$ & 3.95 & $3.37^{\star}$ & 6.72 & $3 \cdot 29^{*}, \dagger$ & 6.43 & 4.41 & 5.87 & $4.09^{*}$ & 7.97 & $2 \cdot 69^{*}, \dagger$ \\
\hline $\mathrm{Na}$ & 10 & 8.86 & $2 \cdot 12$ & 8.45 & 2.54 & 7.04 & $3 \cdot 17^{*}, \dagger$ & 8.97 & 2.41 & 8.44 & $2 \cdot 51^{*}$ & 7.05 & $3 \cdot 12^{*}, \dagger$ \\
\hline Added sugars & 10 & 7.69 & 2.56 & 5.80 & $3.32^{*}$ & 6.52 & $3 \cdot 17^{*}$ & 8.39 & $2 \cdot 15$ & $7 \cdot 11$ & $2 \cdot 92^{*}$ & 5.08 & $3 \cdot 16^{*}$ \\
\hline Saturated fats & 10 & 8.09 & 2.49 & 6.44 & $3.05^{\star}$ & 5.01 & $3 \cdot 10^{*}, \dagger$ & 8.94 & $2 \cdot 12$ & $7 \cdot 27$ & $2 \cdot 42^{*}$ & 6.06 & $3 \cdot 71^{*}, \dagger$ \\
\hline
\end{tabular}

HEI-2015, Healthy Eating Index-2015.

*Indicates significant difference with the first category.

†Indicates significant difference with the second category. The significance was assessed at $P<0.05$ using the Bonferroni post hoc test of ANOVA for mean comparison of the groups.

†Includes $100 \%$ fruit juice.

§Includes all forms except juice.

IIIncludes only vegetables.

IIncludes maize tortillas, whole bread and cereal bars $\geq 6 \mathrm{~g} \%$ of fibre.

${ }^{\star}$ Includes all milk products, such as fluid milk, yogurt and cheese.

t†Includes only animal protein food.

¥¥Includes only seafood and nuts.

IIIIModeration components scores of HEI-2015 indicate that higher intakes are related to lower scores and vice versa. 
Table 3 Multivariate association between quintiles of diet cost and HEI-2015 in adults (18-59 years) by urban and rural areas, ENSANUT 2012

\begin{tabular}{|c|c|c|c|c|c|c|}
\hline & \multicolumn{3}{|c|}{ Urban (n 1636) } & \multicolumn{3}{|c|}{ Rural (n 802) } \\
\hline & \multicolumn{2}{|c|}{ HEI-2015 score } & \multirow[b]{2}{*}{$P$-value } & \multicolumn{2}{|c|}{ HEI-2015 score } & \multirow[b]{2}{*}{$P$-value } \\
\hline & Adjusted coefficient & $95 \% \mathrm{Cl}$ & & Adjusted coefficient & $95 \% \mathrm{Cl}$ & \\
\hline \multicolumn{7}{|c|}{ Quintiles of diet cost (\$MXN/2000 kcal) } \\
\hline Quintile 1 & Reference & & & & & \\
\hline Quintile 2 & 1.17 & $-1 \cdot 01,3 \cdot 35$ & 0.293 & $-2 \cdot 76$ & $-5 \cdot 73,0.21$ & 0.068 \\
\hline Quintile 3 & $2 \cdot 14$ & $-0.06,4.33$ & 0.056 & -0.73 & $-3.79,2.34$ & 0.641 \\
\hline Quintile 4 & $4 \cdot 70$ & $2.62,6.79$ & $<0.001$ & 1.75 & $-2 \cdot 20,5 \cdot 70$ & 0.385 \\
\hline Quintile 5 & $6 \cdot 34$ & $4 \cdot 20,8 \cdot 49$ & $<0.001$ & -1.39 & $-4.57,1.79$ & 0.39 \\
\hline$P$-trend & & & $<0.001$ & & & 0.866 \\
\hline \multicolumn{7}{|l|}{ Age (years) } \\
\hline $18.0-<29.6$ & Reference & & & & & \\
\hline $29.6-<43.5$ & 2.35 & $0.70,4.00$ & 0.005 & -0.33 & $-2.64,1.98$ & 0.777 \\
\hline $43.5-59 \cdot 0$ & $1 \cdot 13$ & $-0.61,2.87$ & 0.204 & 1.72 & $-0.94,4.38$ & 0.204 \\
\hline \multicolumn{7}{|c|}{ Socio-economic index } \\
\hline Low & Reference & & & Reference & & \\
\hline Medium & $-1 \cdot 88$ & $-3 \cdot 68,-0.07$ & 0.042 & $-2 \cdot 22$ & $-4.72,0.29$ & 0.083 \\
\hline High & -1.03 & $-2.89,0.83$ & 0.276 & $-4 \cdot 76$ & $-8 \cdot 15,-1 \cdot 37$ & 0.006 \\
\hline \multicolumn{7}{|l|}{ Sex } \\
\hline Male & Reference & & & & & \\
\hline Female & 0.86 & $-0.37,2.09$ & 0.170 & -0.64 & $-2.29,1.64$ & 0.580 \\
\hline \multicolumn{7}{|l|}{ Education level } \\
\hline Low & Reference & & & & & \\
\hline Medium & 1.44 & $-2.03,4.90$ & 0.416 & -3.85 & $-7 \cdot 85,0.14$ & 0.059 \\
\hline High & 0.99 & $-2 \cdot 83,4 \cdot 81$ & 0.611 & -2.68 & $-6.97,1.61$ & 0.220 \\
\hline \multicolumn{7}{|l|}{ Region } \\
\hline North & Reference & & & & & \\
\hline Centre & $4 \cdot 39$ & $2 \cdot 83,5.94$ & $<0.001$ & 7.55 & $4.69,10.42$ & $<0.001$ \\
\hline Mexico City & $1 \cdot 70$ & $-0.34,-0.34$ & 0.103 & * & & * \\
\hline South & $5 \cdot 66$ & $3 \cdot 85,3 \cdot 85$ & $<0.001$ & $9 \cdot 43$ & $6 \cdot 41,12 \cdot 45$ & $<0.001$ \\
\hline \multicolumn{7}{|l|}{ Ethnicity (\%) } \\
\hline Indigenous & Reference & & & & & \\
\hline Non-indigenous & -5.35 & $-8 \cdot 43,-2 \cdot 27$ & $<0.001$ & $-3 \cdot 82$ & $-6.74,-0.91$ & 0.010 \\
\hline Constant & $49 \cdot 6$ & $43 \cdot 9,55 \cdot 2$ & $<0.001$ & $60 \cdot 52$ & $54 \cdot 71,66 \cdot 34$ & $<0.001$ \\
\hline
\end{tabular}

HEI-2015, Healthy Eating Index-2015.

Estimations based on a multiple linear regression model adjusted for the survey design and all the variables in this table.

*Mexico City is only considered as urban, with no rural areas.
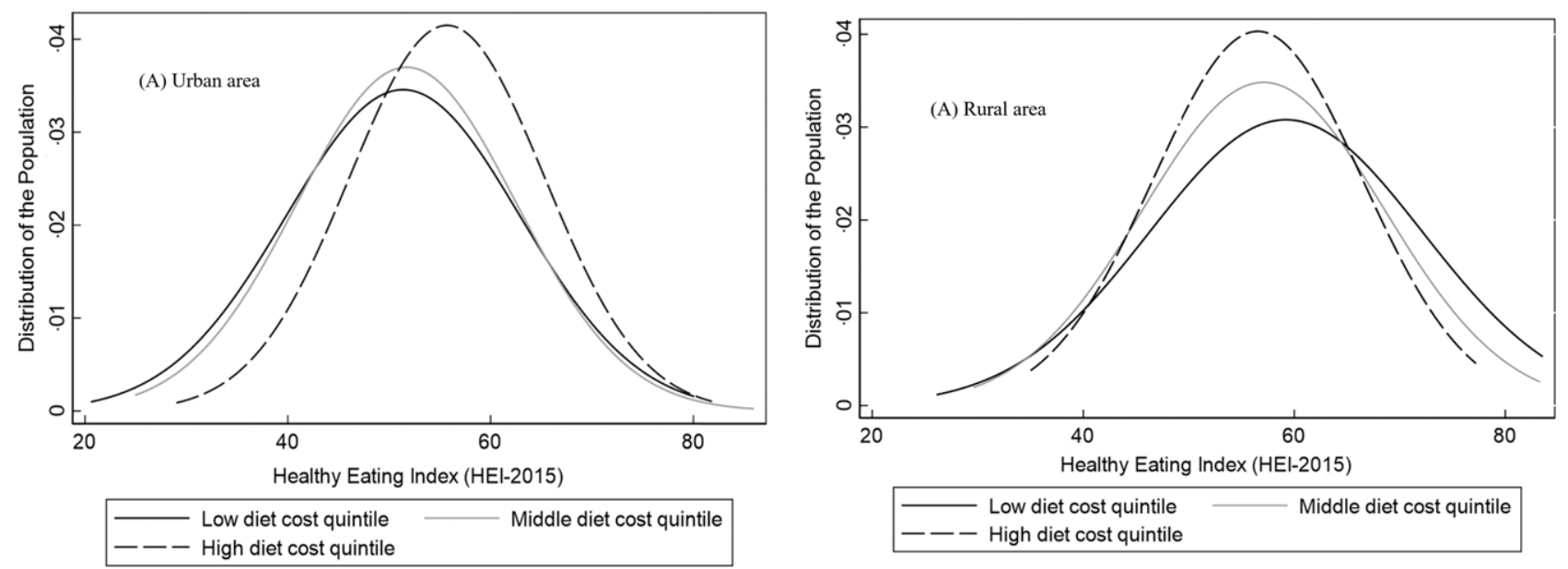

Fig. 1 Distribution of Healthy Eating Index-2015* score by low, middle and high quintiles of diet by area of residence. *Diet quality was adjusted by socio-demographic variables using the multiple linear regression model adjusted for sex, age, socio-economic status, education and ethnicity 

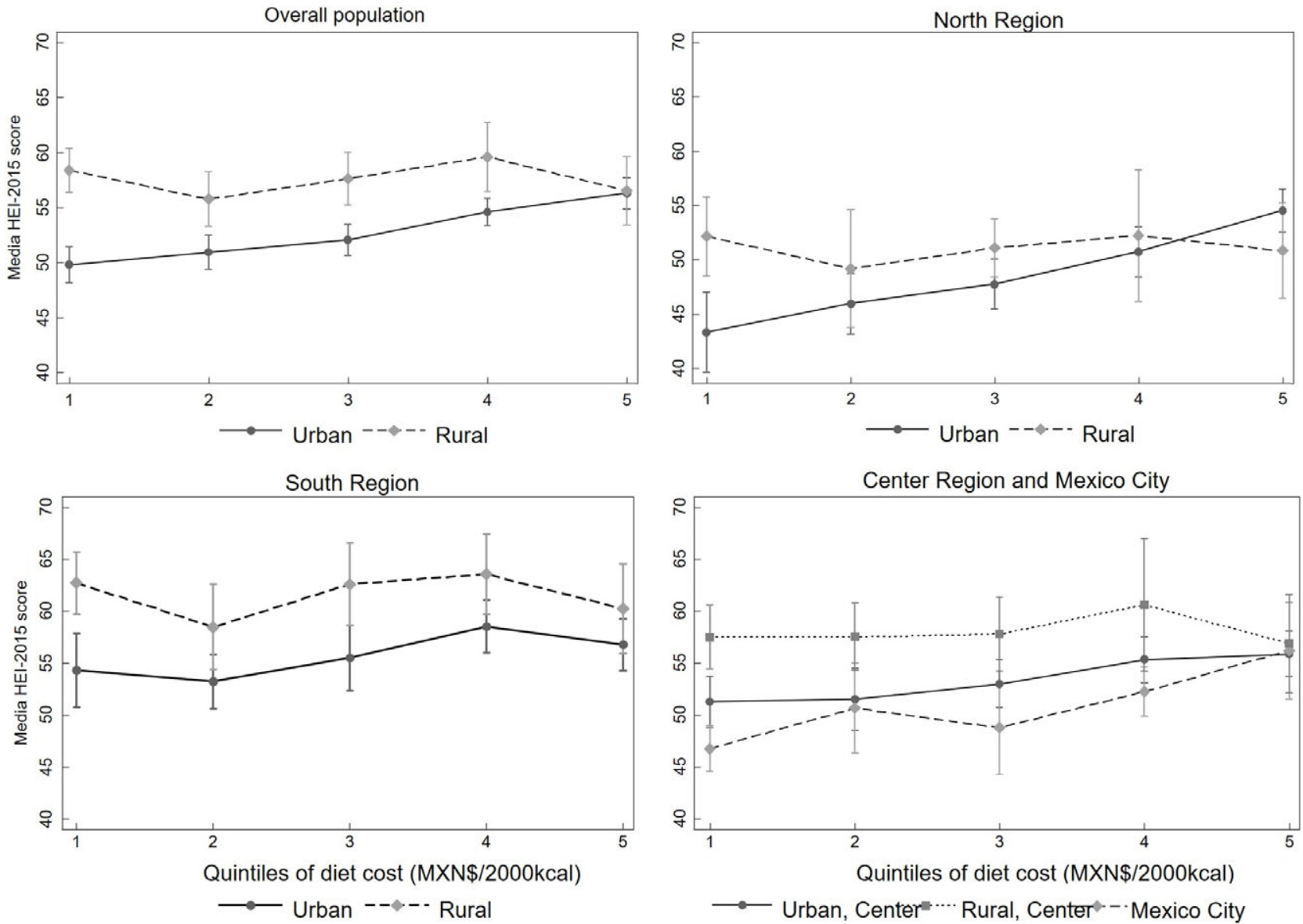

Fig. 2 Association between diet cost quintiles and Healthy Eating Index-2015 (HEl-2015) in adults by area and region of residence ENSANUT 2012. Predicted means of HEI-2015 score by quintiles of diet cost stratified by area and region of residence, estimated from linear regression models adjusted for sex, age, socio-economic status, education and ethnicity. In the figure of the overall population, the model includes the region; for the rest of the regions, we included the area of residence except for Mexico City, which only have urban population

rural Victoria (Australia) reported that diets were unhealthy and cost more than healthier diets ${ }^{(8)}$, while in poor rural areas of the USA and Australia, it was reported a low access to affordable healthy options ${ }^{(43-45)}$. In contrast, our study showed that even though diet quality in rural areas did not reach an optimal score (HEI $>80)$, rural populations had a higher diet quality at a lower cost compared with urban areas, which is explained by differences in the composition of the diet between urban and rural areas. Compared to urban areas, adults from rural areas consume not only more whole grains (mainly from maize), beans and less dairy products and animal proteins but also less sugar, $\mathrm{Na}$ and saturated fats that are major components of highly processed foods. This is consistent with Mendoza et al. who reported that rural adults in Mexico eat more traditional and low-cost energy-dense foods ${ }^{(21)}$.

In addition, having diets with a higher cost does not necessarily imply a higher quality score in all dietary components. We found that adults with more expensive diets, as well as those with higher SES, have not only a greater consumption of healthy components of the HEI-2015 such as fruits and whole fruits, vegetables, dairy products, animal proteins, seafood and nuts, but also a greater consumption of unhealthy dietary components such as $\mathrm{Na}$, added sugar, saturated fats, and a lower ratio of unsaturated fatty acids to SFA. Another study in Mexico also found that individuals with high SES and those living in urban areas have a greater consumption of not only fruits, legumes and dairy products but also products high in sugar and saturated fat ${ }^{(14)}$ which mainly come from processed and ultra-processed products ${ }^{(46)}$. In contrast, in high-income countries such as the USA, the higher quality diets had higher adherence to most of the dietary components, except for $\mathrm{Na}$ intake, which could be related to their higher consumption of processed food ${ }^{(10)}$.

The relation between outcomes and SES was complex. In urban areas, more expensive diets showed better quality at all levels of SES, but in rural areas, for indigenous groups and those living in the South (all low-income groups), a higher diet quality was associated with the same or even lower cost. These relationships could be partly explained by differences in the effect of prices and income on food consumption. Previous studies in Mexico have shown that nutrient-rich foods such as fruits, vegetables and nuts are 
more expensive and have become less affordable than unhealthy options such as ultra-processed products ${ }^{(20,21)}$, so individuals with a greater consumption of nutrientdense foods will have a more expensive diet. However, income is also a driver of food choice, and in a previous study in Mexico, products high in sugar, fat and $\mathrm{Na}$, as well as fruits, animal protein and dairy products, were income elastic $(>1)$; thus, individuals with a higher income had greater consumption of these products ${ }^{(47)}$.

Differences with the results in other countries as well as the mixed results by area and region of residence we presented in this study suggest that the association between diet cost and diet quality as well as other related factors is country specific and that there is heterogeneity even within a country. This heterogeneity could be explained by differences in food availability, physical and economic access to food affected by the geographical conditions, as well as individual factors such as socio-economic and cultural conditions that shape food patterns as well as the different stages of nutritional transition ${ }^{(15,48-50)}$. This is particularly important in middle-income countries such as Mexico where this heterogeneity in the drivers of food choice may affect the effectiveness of strategies to promote better quality diets ${ }^{(42)}$.

In relation to the above, in Mexico, the rural and the South sub-populations live in the poorest socio-economic conditions and had a higher proportion of indigenous population in the country ${ }^{(51)}$. In contrast, the urban areas and the North have similar characteristics of more urbanised countries and have a higher income than other regions ${ }^{(51)}$. The differences in diet quality by socio-demographic conditions show the different stages of the nutritional transition within the country where urbanisation and economic growth were associated with some negative changes in dietary patterns that lead to a higher prevalence of obesity, non-communicable diseases and the coexistence with nutritional deficiencies $^{(48,52)}$. For instance, diets of adults in urban areas and the North region are in a higher stage of the nutritional transition in comparison with diets of adults in rural areas and the South, which preserve characteristics of traditional and healthier diets such as higher consumption of whole grains, vegetables and beans and a lower intake of $\mathrm{Na}$, added sugar and saturated fats. This is consistent with previous studies that show differences in diet quality, as well as the heterogeneous process of nutritional transition that is linked with a higher prevalence of obesity in the wealthier and more urbanised regions ${ }^{(48,53)}$. However, the influence of cultural factors associated with the place of residence and ethnicity and how they impact the quality of diet requires further analysis ${ }^{(54,55)}$. Additionally, the difference in diet quality and diet cost can also be influenced by the characteristics of the food supply. The food production in Mexico mainly takes place in rural areas, so families could have access to their own food production. Also, in the Northern region, the supermarkets are the main supply of food, while in the Southern region, the open markets are more present.
In all the regions, grocery stores are major food suppliers for households ${ }^{(51)}$. This heterogeneity in the food supply is also associated with different food prices and food quality $^{(52)}$. We can hypothesise that this heterogeneity provides the possibility of improving diet quality at the same or even lower cost compared with urban areas. Additionally, a study of food environments in Mexico showed that in rural areas, there is access to healthy food options, but there is greater access and exposure to unhealthy options ${ }^{(53)}$. This is different in the rural areas of the USA where a limited access to affordable healthy food was identified as a main problem ${ }^{(54)}$. However, unless any action is taken to improve the consumption of healthier options, the dietary patterns of rural areas could worsen as economic conditions improve and unhealthy products become more affordable ${ }^{(20)}$.

In addition, it is interesting to note that low SES and being indigenous seem to protect the adults from adopting lower quality diets, mainly due to their history of undernutrition. However, it is important to note that on average, the diet quality in the adult Mexican population was suboptimal ( 54.1 out of 100 points), even in those sub-populations with higher diet quality, such as indigenous population, as well as those from the South and rural areas $(62 \cdot 2,57 \cdot 7$ and 59.7 points, respectively). So, those sub-populations have relatively higher diet quality, but this is still not optimal. This could explain the persistence of the current nutritional problems such as micronutrient deficiencies, especially the low intake of bioavailable $\mathrm{Fe}$ and vitamin $\mathrm{B}_{12}{ }^{(55)}$, and overweight/obesity which is on a rapid increase ${ }^{(56)}$. Furthermore, our results of diet quality are determined by the HEI-2015 which assessed the overall diet based on the adherence to the recommendation of the Dietary Guidelines for Americans considering both adequacy and moderation components that are related to the prevention of nutritional deficiencies, overweight and non-communicable diseases. These recommendations are in line with the latest international ones considered also in the Mexican dietary guidelines ${ }^{(57)}$. Also studies that adapted the HEI-2015 to the Mexican dietary recommendation showed also a suboptimal diet quality with the same association with socio-demographic factors (higher diet quality in rural areas, the South region and those with low $\mathrm{SES})^{(16,58)}$. Similar results were reported using other methods to assess the diet quality such as a posteriori dietary patterns and by food groups ${ }^{(14,15,59)}$. This suggest that the use of the HEI-2015 gives consistent results of diet quality in the context of Mexican adult population considering their major health problems.

This study has some limitations and strengths. We derived the food prices from a national expenditure survey (ENIGH 2012), which did not collect the food prices directly. This may have introduced measurement error; however, prices were estimated at the municipality level to reduce bias at the household level. Furthermore, in the estimation of food prices, we included the monetary values of food that was reported as home-produced food. 
Also, a sensitivity analysis using food prices directly collected by the INEGI in urban cities did not change our results. In addition, the SFFQ includes a limited list of foods and thus could lead to underestimating food intake. However, these foods represented more than $90 \%$ of the total energy and nutrient intake and are a measure of habitual intake. Likewise, the amount of $\mathrm{Na}$ intake is underestimated because we did not include the salt added to food. As those errors affect all of the study population, and the cost of salt is minimal, we do not expect any differential bias. There is also a potential response bias for a differential misreporting of the amount of food consumed by place of residence that could lead to under or overestimation of the price as well as the HEI-2015. The stratified analysis by place of residence and the adjustment for energy and socio-economic covariates may reduce these effects. Despite those limitations, this is the first study that analysed the association between diet cost and overall diet quality in a representative sample of the Mexican adult population that could be used as a baseline for future research in this field. Also, the use of standardised methods reduced the potential selection bias and measurement errors, and we included sensitivity analyses to test the consistency of our results.

\section{Policy implications and future research}

Our results revealed some potential practical implications. Further studies are needed to better understand the relation of diet cost and diet quality, as well as the main drivers of diet quality in rural areas and regions, and between levels of SES in Mexico. A deeper analysis of the diets as well as the strategies and conditions that allow some sub-populations to have higher quality diets at a lower cost could provide useful information for the design of interventions to promote better diets. Continuation of policies to reduce the consumption of nutritionally poor, processed foods and sugary beverages, such as taxes, front of pack labelling and regulations to the school's food environment, complemented with policies to increase the consumption of healthy food groups, such as subsidies to fruits and vegetables in urban areas to make them more affordable and the implementation of healthy and sustainable food-based dietary recommendations for Mexican population ${ }^{(52)}$ should consider the heterogeneity in the drivers of diet quality by place of residence. Also, strengthening the population's capacity to make better food choices considering their cultural characteristics could improve the effectiveness of policies aiming to promote better quality diets in Mexico.

\section{Conclusions}

Diet cost was positively associated with diet quality, but only in urban areas, with the strongest association in the North, Mexico City and the Central region. Being indigenous, having a low SES, living in the South and in rural areas were also associated with higher quality diets. Current food policies in Mexico could prove more effective by including elements to improve the consumption of healthy food groups that consider the heterogeneity in the drivers of diet quality by place of residence.

\section{Acknowledgements}

Acknowledgements: The authors would like to thank Carolina Batis and Joaquin Marron from the National Institute of Public Health for their assistance in setting up the database of food prices for the present analysis. Financial support: This is part of a research doctoral thesis from Katherine Curi who received a PhD scholarship from the Mexican National Council of Science and Technology (grant number 797149/616402). The funder had no role in the study design, analyses or interpretation of this article. Conflict of interest: There are no conflicts of interest. Authorship: K.C.Q. and M.U.M. designed the study. K.C.Q. conducted the data analysis and drafted the manuscript. M.U.M. and S.R.R. supervised the data analysis, interpretation and drafting of the manuscript. E.R., J.A.R. and W.W. contributed to the interpretation of the results and assisted in drafting the manuscript. K.C.Q. and M.U.M. are primarily responsible for the final content. All authors read and approved the final manuscript. Ethics of human subject participation: Not applicable. This study is based on the analysis of secondary data of the National Health and Nutrition Survey (ENSANUT) provided by the National Institute of Public Health (INSP by its Spanish acronym). The study protocol of the ENSANUT was approved by the Ethics Committee of the INSP in Mexico, and only participants who agreed and signed an informed consent were included in the survey.

\section{Supplementary material}

For supplementary materials referred to in this article, please visit https://doi.org/10.1017/S1368980021004651

\section{References}

1. Afshin A, Sur PJ, Fay KA et al. (2019) Health effects of dietary risks in 195 countries, 1990-2017: a systematic analysis for the Global Burden of Disease Study 2017. Lancet 393, 1958-1972.

2. Popkin BM (2006) Global nutrition dynamics: the world is shifting rapidly toward a diet linked with noncommunicable diseases. Am J Clin Nutr 84, 289-298.

3. FAO, IFAD, UNICEF et al. (2020) The State of Food Security and Nutrition in the World 2020. Transforming Food Systems for Affordable Healthy Diets. Rome: FAO. 
4. Drewnowski A \& Darmon N (2005) Food choices and diet costs: an economic analysis. J Nutr 135, 900-904.

5. Darmon N \& Drewnowski A (2015) Contribution of food prices and diet cost to socioeconomic disparities in diet quality and health: a systematic review and analysis. Nutr Rev 73, 643-660.

6. Rao M, Afshin A, Singh G et al. (2013) Do healthier foods and diet patterns cost more than less healthy options? A systematic review and meta-analysis. BMJ Open 3, 4277.

7. Murakami K, Sasaki S, Okubo H et al. (2007) Monetary costs of dietary energy reported by young Japanese women: association with food and nutrient intake and body mass index. Public Health Nutr 10, 1430-1439.

8. Love P, Whelan J, Bell C et al. (2018) Healthy diets in rural Victoria - cheaper than unhealthy alternatives, yet unaffordable. Int J Environ Res Public Health 15, 2469.

9. Monsivais P, Rehm CD \& Drewnowski A (2013) The DASH diet and diet costs among ethnic and racial groups in the United States. JAMA Intern Med 173, 1922-1924.

10. Rehm CD, Monsivais P \& Drewnowski A (2015) Relation between diet cost and healthy eating index 2010 scores among adults in the United States 2007-2010. Prev Med 73, 70-75.

11. Bernstein AM, Bloom DE, Rosner BA et al. (2010) Relation of food cost to healthfulness of diet among US women. $A m \mathrm{~J}$ Clin Nutr 92, 1197-1203.

12. Lee S, Kim JY, Lee H et al. (2013) Food Prices and Population Health in Developing Countries: An Investigation of the Effects of the Food Crisis Using a Panel Analysis. Asian Development Bank Economics Working Paper Series No. 374. Manila. http://hdl.handle.net/11540/2069 (accessed August 2020).

13. Shamah-Levy T, Vielma-Orozco E, Heredia-Hernández O et al. (2020) Encuesta Nacional de Salud y Nutrición 2018-2019: Resultados Nacionales (National Health and Nutrition Survey 2018-2019: National Results). Cuernavaca, Mexico: Instituto Nacional de Salud Pública.

14. Batis C, Aburto TC, Sánchez-Pimienta TG et al. (2016) Adherence to dietary recommendations for food group intakes is low in the Mexican population. J Nutr 146, 1897S-1906S.

15. Flores M, Macias N, Rivera M et al. (2010) Dietary patterns in Mexican adults are associated with risk of being overweight or obese. J Nutr 140, 1869-1873.

16. Lopez-Olmedo N, Popkin BM \& Taillie LS (2019) Association between socioeconomic status and diet quality in Mexican men and women: a cross-sectional study. PLOS ONE 14, $\mathrm{e} 0224385$.

17. Kourlaba G \& Panagiotakos DB (2009) Dietary quality indices and human health: a review. Maturitas 62, 1-8.

18. Burggraf C, Teuber R \& Brosig S (2018) Review of a priori dietary quality indices in relation to their construction. Nutr Rev 1, 747-764.

19. Panizza CE, Shvetsov YB, Harmon BE et al. (2018) Testing the predictive validity of the healthy eating index-2015 in the multiethnic cohort: is the score associated with a reduced risk of all-cause and cause-specific mortality? Nutrients $\mathbf{1 0}$, 452.

20. Colchero M, Guerrero-López C, Molina M et al. (2019) Affordability of food and beverages in Mexico between 1994 and 2016. Nutrients 11, 78.

21. Mendoza A, Pérez AE, Aggarwal A et al. (2017) Energy density of foods and diets in Mexico and their monetary cost by socioeconomic strata: analyses of ENSANUT data 2012. J Epidemiol Community Health 71, 713-721.

22. Coneval Consejo Nacional de Evaluación de Política Social (2018) Evolución de las Líneas de Bienestar y de la Canasta Alimentaria (Evolution of the well-being threshold and food basket). https://www.coneval.org.mx/Medicion/MP/ Paginas/Lineas-de-bienestar-y-canasta-basica.aspx (accessed March 2018).
23. Gutiérrez JP, Rivera-Dommarco J, Shamah-Levy $\mathrm{T}$ et al. (2012) Encuesta Nacional de Salud y Nutrición: Resultados Nacionales 2012. 1-200 (National Health and Nutrition Survey: National Results 2012). Cuernavaca, México: Instituto Nacional de Salud Pública.

24. Ramírez-Silva I, Jiménez-Aguilar A, Valenzuela-Bravo D et al. (2016) Methodology for estimating dietary data from the semi-quantitative food frequency questionnaire of the Mexican National Health and Nutrition Survey 2012. Salud Publica Mex 58, 629.

25. Campos-Nonato I, Hernández-Barrera L, Pedroza-Tobías A et al. (2018) Hypertension in Mexican adults: prevalence, diagnosis and type of treatment. Ensanut MC 2016. Salud Publica Mex 60, 233-243.

26. Rojas-Martínez R, Basto-Abreu A, Aguilar-Salinas CA et al. (2018) Prevalence of previously diagnosed diabetes mellitus in Mexico. Salud Pubica Mex 60, 224-232.

27. National Cancer Institute (2018) Overview \& Background of Healthy Eating Index (HEI). https://epi.grants.cancer.gov/ hei/ (accessed April 2018).

28. Reedy J, Lerman JL, Krebs-Smith SM et al. (2018) Evaluation of the healthy eating index-2015. J Acad Nutr Diet 118, $1622-1633$.

29. National Cancer Institute (2018) Basic Steps in Calculating HEI Scores. https://epi.grants.cancer.gov/hei/calculatinghei-scores.html (accessed April 2018).

30. Bowman SA, Clemens JC, Friday JE et al. (2017) Food Patterns Equivalents Database 2013-2014: Methodology and User. Beltsville, MD: Food Surveys Research Group, Beltsville Human Nutrition Research Center, Agricultural Research Service, U.S. Department of Agriculture.

31. Louie JCY, Moshtaghian H, Boylan S et al. (2015) A systematic methodology to estimate added sugar content of foods. Eur J Clin Nutr 69, 154-161.

32. Organización Panamericana de la Salud (2016) Modelo de perfil de nutrientes de la OPS (PAHO Nutrient profile model). OPS. https://www.paho.org/es/perfil-de-nutrientes (accessed July 2020).

33. INEGI (2012) Encuesta Nacional de Ingresos y Gastos de los Hogares (ENIGH) 2012 (National Survey of Household Income and Expenditure 2012). https://www.inegi.org.mx/ $\mathrm{rnm} /$ index.php/catalog/74/study-description (accessed September 2016).

34. Sedesol (2013) Liconsa will keep the price of a liter of milk at 4.50 pesos. Press release. Comunicado de prensa. Unidad Comun. Soc. http://www.sedesol.gob.mx/work/models/ SEDESOL/Sala_Prensa/Comunicados/pdf/261213-Liconsa_ precio.pdf (accessed August 2019).

35. INEGI (2013) Índice Nacional de Precios al Consumidor (INPC). Documento metodológico (National Consumer Price Index. Methodological Document). Ciudad de México, México. https://www.inegi.org.mx/contenidos/programas/ inpc/2010/doc/documento_metodologico_inpc.pdf(accessed October 2018).

36. INEGI \& CONABIO (2012) Localidades de la República Mexicana, 2010 (Localities from the Mexican Republic, 2010). Comisión Nacional para el Conocimiento y Uso de la Biodiversidad.http://conabio.gob.mx/informacion/metadata/ gis/loc2010gw.xml?_xsl=/db/metadata/xsl/fgdc_html.xsl\&_ indent $=$ no\&as $=. h t m l$ (accessed November 2018).

37. Díaz-Acosta R, Shiba-Matsumoto AR \& Gutiérrez JP (2015) Medición simplificada del nivel socioeconómico en encuestas breves: propuesta a partir de acceso a bienes y servicios (Simplified indicator of socioeconomic status in short surveys: a proposal based on assets and services). Salud Publica Mex 57, 298-303.

38. Rubio Badan JC (2013) Censos y población indígena en México. Algunas reflexiones (Census and Indigenous Population in Mexico. Some Reflexions). Estud. Y Perspect. Mexico: CEPAL. 
39. INEGI (2020) Población rural y urbana (Urban and rural population). http://cuentame.inegi.org.mx/poblacion/rur_urb. aspx (accessed October 2018).

40. Brabin BJ, Hakimi M \& Pelletier D (2001) Dietary energy density determined by eight calculation methods in a nationally representative United States population. J Nutr 131, 604S-615S.

41. Beydoun MA, Fanelli-Kuczmarski MT, Allen A et al. (2015) Monetary value of diet is associated with dietary quality and nutrient adequacy among urban adults, differentially by sex, race and poverty status. PLoS One 10, e0140905.

42. Mackenbach JD, Dijkstra SC, Beulens JWJ et al. (2019) Socioeconomic and ethnic differences in the relation between dietary costs and dietary quality: the HELIUS study. Nutr J 18, 21.

43. Whelan J, Millar L, Bell C et al. (2018) You can't find healthy food in the bush: poor accessibility, availability and adequacy of food in rural Australia. Int I Environ Res Public Health 15, 2316.

44. Hardin-Fanning F \& Rayens MK (2015) Food cost disparities in rural communities. Health Promot Pract 16, 383-391.

45. Lenardson JD, Hansen AY \& Hartley D (2015) Rural and remote food environments and obesity. Curr Obes Rep $\mathbf{4}$, 46-53.

46. Marrón-Ponce JA, Flores M, Cediel G et al. (2019) Associations between consumption of ultra-processed foods and intake of nutrients related to chronic non-communicable diseases in Mexico. J Acad Nutr Diet 119, 1852-1865.

47. Unar-Munguía M; Colchero A; Teruel G et al. (2012) El efecto de los precios de alimentos 2002-2005 en el indice de masa corporal y prevalencia de sobrepeso y obesidad de mujeres en México. Tesis de Maestría (Food Prices Effect on BMI and the Prevalence of Overweight and Obesity in Women in Mexico. 2002-2005. Master Thesis). Cuernavaca, Mexico: National Institute of Public Health.

48. Rivera JA, Barquera S, Campirano F et al. (2002) Epidemiological and nutritional transition in Mexico: rapid increase of non-communicable chronic diseases and obesity. Public Health Nutr 5, 113-122.

49. USDA Foreign Agricultural Services (2010) Food Security and Nutrition in Mexico. Mexico: USDA.
50. Fanzo J \& Davis C (2019) Can diets be healthy, sustainable, and equitable? Curr Obes Rep 8, 495-503.

51. FAO (2019) El sistema alimentario en México-Oportunidades para el campo mexicano en la Agenda 2030 de Desarrollo Sostenible (The Food System in Mexico - Oportunities for the Mexican Countryside in the 2030 Agenda for Sustainable Development). Ciudad México: FAO. https://www.fao.org/ publications/card/es/c/CA2910ES/ (accessed August 2020).

52. Rivera Dommarco JÁ, Colchero A, Fuentes LM et al. (2018) Obesidad en México. Estado de la política pública y recomendaciones para su prevención y control (Obesity in Mexico. State of Public Policy for Preventionand Control), 1st ed. Cuernavaca: Instituto Nacional de Salud Pública.

53. Bridle-Fitzpatrick S (2015) Food deserts or food swamps? A mixed-methods study of local food environments in a Mexican city. Soc Sci Med 142, 202-213.

54. Dutko P, Ver Ploeg M \& Farrigan T (2012) Characteristics and Influential Factors of Food Deserts. Washington, DC: Department of Agriculture, Economic Research Service.

55. Shamah-Levy T, Villalpando S, Mejía-Rodríguez $\mathrm{F}$ et al. (2015) Prevalence of iron, folate, and vitamin $B_{12}$ deficiencies in 20 to 49 years old women: ENSANUT 2012. Salud Publica Mex 57, 385-393.

56. Barquera S, Hernández-Barrera L, Trejo B et al. (2020) Obesidad en México, prevalencia y tendencias en adultos. Ensanut 2018-2019 (Obesity in Mexico, prevalence and trends in adults. Ensanut 2018-19). Salud Publica Mex 62, 682-692.

57. Academia Nacional de Medicina (2015) Guias Alimentarias $y$ de actividad física: en contexto de sobrepeso y obesidad en la población mexicana (Dietary and Physical Activity Guidelines: In the Context of Overweight and Obesity in the Mexican Population). Mexico: Academia Nacional de Medicina (ANM).

58. Pérez-Tepayo S, Rodríguez-Ramírez S, Unar-Munguía M et al. (2020) Trends in the dietary patterns of Mexican adults by sociodemographic characteristics. Nutr $J \mathbf{1 9}$, $1-10$.

59. Castellanos-Gutiérrez A, Sánchez-Pimienta TG, Batis C et al. (2021) Toward a healthy and sustainable diet in Mexico: where are we and how can we move forward? Am J Clin Nutr 113, 1177-1184. 